\title{
Study of adverse drug reactions associated with antiepileptic drugs: a pharmacovigilance study using spontaneous reporting system
}

\author{
Sudha K. Mukhyaprana, Siddiraju Devipriya*, Meenakshi Thirumalaiappan
}

Pharmacovigilance Center, Pharmacovigilance Program of India, Institute of Pharmacology, Madras Medical College, Chennai, Tamil Nadu, India

Received: 07 July 2021

Accepted: 06 August 2021

*Correspondence:

Siddiraju Devipriya,

Email: amrutha.priya@gmail.com

Copyright: $(\odot$ the author(s), publisher and licensee Medip Academy. This is an open-access article distributed under the terms of the Creative Commons Attribution Non-Commercial License, which permits unrestricted non-commercial use, distribution, and reproduction in any medium, provided the original work is properly cited.

\begin{abstract}
Background: More than 25 antiepileptic drugs (AEDs) are available in the Indian market to treat epilepsy of which many have similar efficacy but differ in their tolerability and are associated with many adverse drug reactions (ADRs). ADRs are one of the most common causes of death and clinical trials are not sufficient to uncover all the ADRs, hence post-marketing surveillance or pharmacovigilance is necessary. The aim of the study was to analyze the ADRs of AEDs by spontaneous reporting system under Pharmacovigilance Program of India (PvPI).

Methods: Suspected ADR reporting forms provided by PvPI were used to collect the data from healthcare professionals of Madras Medical College and Rajiv Gandhi Government General Hospital, Chennai.

Results: A total of 77 ADRs from 61 reports were analysed of which 34 were male and 27 were female patients and maximum were in the middle-aged adult group $(\mathrm{N}=44)$. Majority of the ADRs were related to skin and subcutaneous disorders $(\mathrm{N}=55)$ and most implicated ADR was found to be maculopapular rash $(\mathrm{N}=12)$ associated with phenytoin. Most of the ADRs were non-serious $(\mathrm{N}=42)$ and were probable category $(\mathrm{N}=45)$ as per WHO-UMC scale.

Conclusions: Monitoring ADRs in patients using antiepileptic drugs is a matter of importance; hence a robust pharmacovigilance practice is essential.
\end{abstract}

Keywords: Adverse drug reactions, Antiepileptic drugs, Pharmacovigilance, Pharmacovigilance program of India

\section{INTRODUCTION}

Adverse drug reactions (ADRs), the hazards of drug therapy are a significant cause of morbidity and mortality and would also result in increased healthcare cost. Some ADRs are minor and resolve without sequelae, but others can cause permanent disability or death. According to WHO, ADR is defined as any noxious, unintended or undesirable effect of a drug that occurs at doses used in humans for prophylaxis, diagnosis, therapy or modification of physiological functions. In broad terms, an ADR is an adverse event with a causal link to the drug. ${ }^{1}$

Antiepileptic drugs (AEDs) are among the most common drugs to induce ADRs due to their narrow therapeutic index, affecting any organ and system. Their widespread use has significant safety implications. Overall, 10-30\% of people with epilepsy discontinue their initially prescribed AED due to intolerance. ${ }^{2}$

More than 20 Food and Drug Administration (FDA) approved antiepileptic drugs are available in the current market. The patient may experience ADRs with single or multiple drugs as anticipated or may show up instantly on continued use or even after cessation of therapy. According to WHO, pharmacovigilance is the science and activities relating to the detection, assessment, understanding and prevention of adverse effects or any other possible drug-related problems. Monitoring of ADRs helps to evaluate the risk-benefit of medications, empower safe and rational use of drugs and enhance general patient care and well-being. ${ }^{3}$ 
The unexpected ADRs for the new drugs are yet to be well documented; hence the ADR monitoring system will be beneficial for the treating physician. Some adverse drug reactions have been identified after use by a large number of people in the phase IV clinical trial, so the documentation of ADR is more emphasized. ${ }^{4}$

Patients receiving AEDs suffer from various ADRs. Most of the ADRs of AEDs belong to type A category, which are acute, predictable, dose dependent and related to the known pharmacologic properties of these drugs. Although type A effects can have a major impact on patients' quality of life, they are usually reversible upon dosage adjustment and they rarely require discontinuation of therapy. On the other hand, unpredictable and idiosyncratic type B reactions whose pathogenesis is apparently unrelated to the known mechanisms of action of the offending drug, occur in 3\%-10\% of the patients treated with AEDs, which range from mild maculopapular eruptions to serious and life-threatening severe cutaneous adverse drug reactions (SCARs)..$^{5-7}$

\section{Aim and objective}

The aim of the study was to analyze the adverse drug reactions due to AEDs by spontaneous ADR reporting system.

\section{METHODS}

A prospective observational study was conducted at Madras Medical College (MMC) and Rajiv Gandhi Government General Hospital (RGGGH), Chennai from January 2019 to March 2021 using suspected adverse drug reaction (sADR) reporting form provided by Pharmacovigilance Program of India (PvPI). All the spontaneous ADRs associated with AEDs reported by HealthCare Professionals (HCPs) were included in the study. Patient demographic details, suspected $\operatorname{drug}(\mathrm{s})$ details and ADR related information filled in SADR reporting form by the HCPs was collected during the study.

All the sADR reporting forms were analyzed for the patient age group, gender, seriousness of the ADR, suspected drugs implicating the ADRs, outcome and the causality assessment (WHO-UMC scale) of the ADRs with drugs. Further, all the ADRs observed were grouped on the basis of system organ class which they affected.

\section{RESULTS}

A total of 78 ADRs were analyzed from 61 reports. Among 61 reports, 34 were male and 27 were female patients under treatment with antiepileptic drug(s) (Figure 1). The age group in which the maximum number of ADRs manifested was middle aged adults (31-59 years of age) $(\mathrm{N}=44)$ followed by young adults $(19-30$ years of age) $(\mathrm{N}=8)$, elderly $(\geq 60$ years of age $)(\mathrm{N}=5)$ and children $(\leq 18$ years of age) $(\mathrm{N}=4)$ (Figure 2$)$.

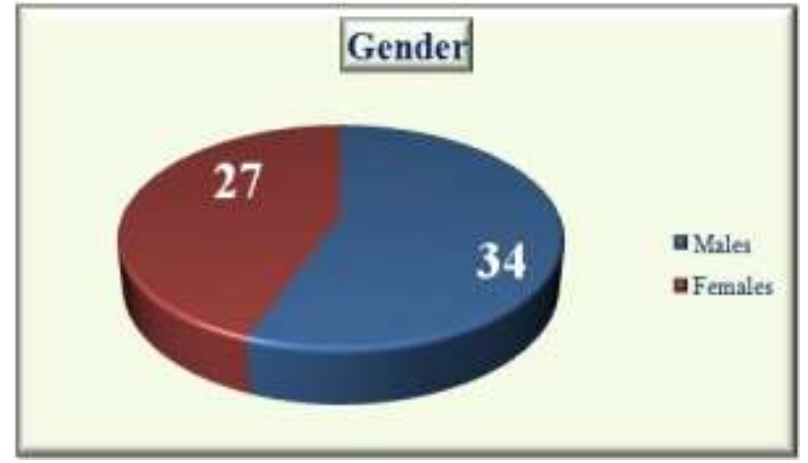

Figure 1: Gender wise distribution of ADRs.

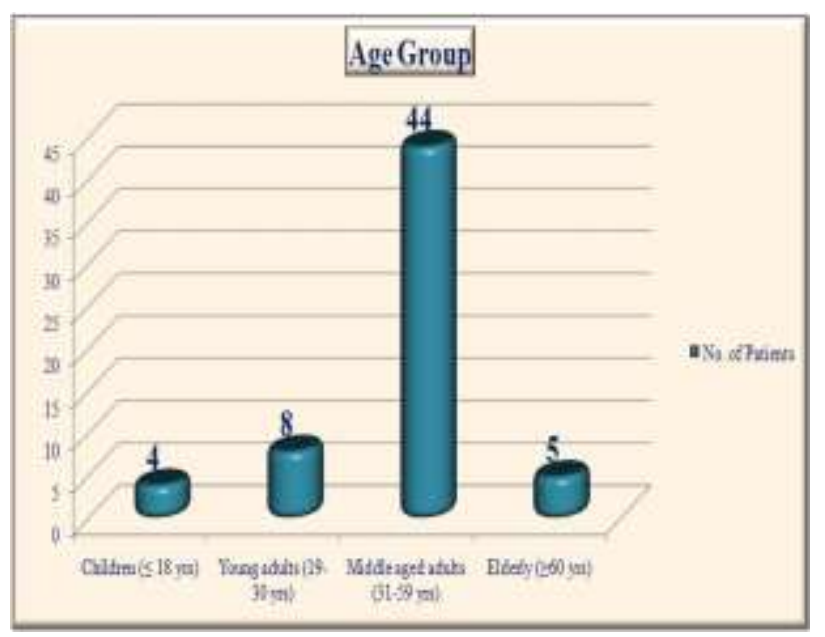

Figure 2: Age wise distribution of ADRs.

The reported ADRs were grouped into System Organ Class (SOC) and the most predominat ADRs belonged to skin and sucutaneous tissue disorders (maculopapular rash $\mathrm{N}=15$, rashes $\mathrm{N}=8$, Toxic Epidermal Necrolysis (TEN) $\mathrm{N}=5$, skin lesions $\mathrm{N}=4$, erosions $\mathrm{N}=4$, itching $\mathrm{N}=3$, erythema/redness N=3, Stevens Johson Syndrome (SJS) $\mathrm{N}=2$, blisters $\mathrm{N}=2$, urticarial rash $\mathrm{N}=2$, erythematous macules $\mathrm{N}=2$, skin scaling $\mathrm{N}=2$, SJS-TEN overlap $\mathrm{N}=1$, bullous eruption $\mathrm{N}=1$ and erythematous rash $\mathrm{N}=1$ ) followed by gastrointestinal disorders (oral ulcers $\mathrm{N}=7$, constipation $\mathrm{N}=2$ and gum hypertrophy $\mathrm{N}=1$ ), nervous system disorders (ataxia $\mathrm{N}=2$, sedation $\mathrm{N}=1$, insomnia $\mathrm{N}=1$ and excessive drowsiness $\mathrm{N}=1$ ), musculoskeletal disorders (muscle weakness $\mathrm{N}=1$ and backache $\mathrm{N}=1$ ), psychiatric disorders (irritability $\mathrm{N}=1$ and incoherence of thought $\mathrm{N}=1$ ), general disorders (fever $\mathrm{N}=1$ ), metabolism and nutrition disorders (vitamin $\mathrm{D}$ deficiency $\mathrm{N}=1$ ) and reprodcutive system and breast disorders (sexual feeling sensation in clitoris $\mathrm{N}=1$ ) (Table 1 ).

It was analysed from the reports that the most of the ADRs implicated were with phenytoin $(\mathrm{N}=52)$ followed by carbamazepine $(\mathrm{N}=13)$, pregabalin $(\mathrm{N}=6)$, sodium valproate $(\mathrm{N}=3)$, gabapentin $(\mathrm{N}=3)$ and thiopentone $(\mathrm{N}=1)$ (Figure 3). 
Table 1: ADRs grouped according to System Organ Class (SOC).

\begin{tabular}{|c|c|}
\hline ADRs-SOC & No. of ADRs \\
\hline \multirow{3}{*}{$\begin{array}{l}\text { Gatrointestinal } \\
\text { disorders }\end{array}$} & Oral ulcers (07) \\
\hline & Constipation (02) \\
\hline & Gum hypertrophy (01) \\
\hline General disorders & Fever $(01)$ \\
\hline $\begin{array}{l}\text { Metabolism and } \\
\text { nutrition disorders }\end{array}$ & Vitamin D deficiency (01) \\
\hline \multirow{2}{*}{$\begin{array}{l}\text { Musculoskeletal } \\
\text { disorders }\end{array}$} & Muscle weakness (01) \\
\hline & Backache $(01)$ \\
\hline \multirow{4}{*}{$\begin{array}{l}\text { Nervous system } \\
\text { disorders }\end{array}$} & Ataxia (02) \\
\hline & Sedation (01) \\
\hline & Insomnia (01) \\
\hline & Excessive drowsiness $(01)$ \\
\hline \multirow[b]{2}{*}{ Psychiatric disorders } & Irritability $(01)$ \\
\hline & $\begin{array}{l}\text { Incoherence of thought } \\
(01)\end{array}$ \\
\hline $\begin{array}{l}\text { Reproductive system } \\
\text { and breast disorders }\end{array}$ & $\begin{array}{l}\text { Sexual feeling sensation in } \\
\text { the clitoris }(01)\end{array}$ \\
\hline \multirow{15}{*}{$\begin{array}{l}\text { Skin and } \\
\text { subcutaneous tissue } \\
\text { disorders }\end{array}$} & Maculopapular rash (15) \\
\hline & Rashes (08) \\
\hline & SJS (02) \\
\hline & TEN (05) \\
\hline & SJS-TEN overlap (01) \\
\hline & Blisters (02) \\
\hline & Urticarial rash (02) \\
\hline & Skin lesions (04) \\
\hline & Redness/erythema (03) \\
\hline & Erythematous macules (02) \\
\hline & Erosions $(04)$ \\
\hline & Itching (03) \\
\hline & Bullous eruption (01) \\
\hline & Erythematous rash (01) \\
\hline & Skin scaling (02) \\
\hline
\end{tabular}

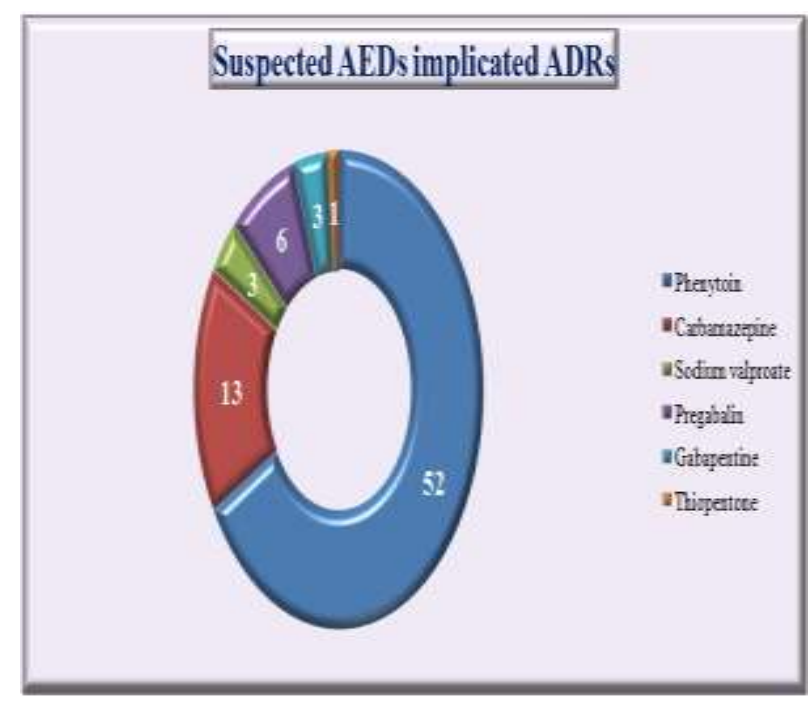

Figure 3: Suspected AEDs implicated ADRs.
It was found that the most implicated ADRs with phenytoin were maculopapular rash $(\mathrm{N}=12)$, oral ulcers $(\mathrm{N}=6)$, rashes $(\mathrm{N}=6)$, ten $(\mathrm{N}=4)$, skin lesions $(\mathrm{N}=3)$, itching $(\mathrm{N}=3)$, SIS $(\mathrm{N}=2)$, blisters $(\mathrm{N}=2)$, urticarail rash $(\mathrm{N}=2)$, redness/erythema $(\mathrm{N}=2)$, erosions $(\mathrm{N}=2)$, ataxia $(\mathrm{N}=2)$, bullous eruption $(\mathrm{N}=1)$, erythematous rash $(\mathrm{N}=1)$, constipation $(\mathrm{N}=1)$, gum hypertrophy $(\mathrm{N}=1)$, irritability $(\mathrm{N}=1)$ and fever $(\mathrm{N}=1)$ (Table 2).

Table 2: Suspected AEDs and the implicated ADRs.

\begin{tabular}{|c|c|}
\hline $\begin{array}{l}\text { Suspected } \\
\text { antiepileptic } \\
\text { drugs }\end{array}$ & No. of ADRs \\
\hline \multirow{18}{*}{ Phenytoin } & Maculopapular rash (12) \\
\hline & Blisters (02) \\
\hline & SJS (02) \\
\hline & TEN (04) \\
\hline & Urticarial rash (02) \\
\hline & Rashes (06) \\
\hline & Skin lesions (03) \\
\hline & Redness/erythema (02) \\
\hline & Erosions $(02)$ \\
\hline & Bullous eruption $(01)$ \\
\hline & Erythematous rash $(01)$ \\
\hline & Itching $(03)$ \\
\hline & Oral ulcers (06) \\
\hline & Constipation $(01)$ \\
\hline & Gum hypertrophy (01) \\
\hline & Ataxia (02) \\
\hline & Irritability (01) \\
\hline & Fever $(01)$ \\
\hline \multirow{10}{*}{ Carbamazepine } & Maculopapular rash (03) \\
\hline & TEN (01) \\
\hline & SJS-TEN overlap (01) \\
\hline & Rashes $(02)$ \\
\hline & Erosions $(01)$ \\
\hline & Erythematous macules (01) \\
\hline & Skin scaling $(01)$ \\
\hline & Skin lesions $(01)$ \\
\hline & Oral ulcers $(01)$ \\
\hline & $\begin{array}{l}\text { Sexual feeling sensation at clitoris } \\
(01)\end{array}$ \\
\hline \multirow{3}{*}{$\begin{array}{l}\text { Sodium } \\
\text { valproate }\end{array}$} & Backache $(01)$ \\
\hline & Muscle weakness (01) \\
\hline & Vitamin D deficiency (01) \\
\hline \multirow{6}{*}{ Pregabalin } & Constipation $(01)$ \\
\hline & Sedation (01) \\
\hline & Insomnia (01) \\
\hline & Redness/erythema (01) \\
\hline & Skin scaling $(01)$ \\
\hline & Incoherence of thought (01) \\
\hline \multirow{3}{*}{ Gabapentine } & Erosions $(01)$ \\
\hline & Erythematous macules (01) \\
\hline & Excessive drowsiness $(01)$ \\
\hline Thiopentone & Thrombophlebitis (01) \\
\hline
\end{tabular}


Among the 61 ADR reports, 34 were categorized into 'serious' as per ICH E2A guidelines, of which maximum number of ADRs are falling under 'Hospitalization/prolonged hospitalization' category $(\mathrm{N}=24)$, 'Disability' and category $(\mathrm{N}=1)$ and 'Other medically important' $(\mathrm{N}=9)$ (Table 3 ).

Table 3: Seriousness of the reaction.

\begin{tabular}{|ll|}
\hline Seriousness criteria & No. of reports \\
\hline Death & 0 \\
\hline Life threatening & 0 \\
\hline Hospitalization/prolonged & 24 \\
\hline Congenital anomaly & 0 \\
\hline Disability & 01 \\
\hline Other medically important & 09 \\
\hline Non-serious & 27 \\
\hline
\end{tabular}

Out of 61 reports, it was found that the suspected AEDs were given for different indications of which majority was found to be seizure prophylaxis $(\mathrm{N}=27)$ (which includes, subdural hematoma, road traffic accident and head injury) followed by seizure disorder $(\mathrm{N}=25)$, generalised tonicclonic seizures $(\mathrm{N}=6)$, acute meningoencephaly $(\mathrm{N}=1)$, complex seizures $(\mathrm{N}=1)$ and trigeminal neuralgia $(\mathrm{N}=1)$ (Table 4).

Table 4: Indication for which the AEDs given.

\begin{tabular}{|ll|}
\hline Indications & No. of reports \\
\hline Seizure disorder & 25 \\
\hline Seizure prophylaxis & 27 \\
\hline Acute meningoencephaly & 1 \\
\hline Generalised tonic-clonic seizures & 6 \\
\hline Complex seizures & 1 \\
\hline Trigeminal neuralgia & 1 \\
\hline
\end{tabular}

It was also found that among the 61 reports, the suspected 'drug withdrawn' were 49, 'dose decreased' were 3 , 'drug changed' were 5 and 'dose not changed' were 4 reports (Table 5).

Table 5: Action taken-suspected drugs.

\begin{tabular}{|ll|}
\hline Actions taken & No. of reports \\
\hline Drug withdrawn & 49 \\
\hline Dose decreased & 03 \\
\hline Drug changed & 05 \\
\hline Dose not stopped & 04 \\
\hline Not applicable & 0 \\
\hline Unknown & 0 \\
\hline
\end{tabular}

The causality assessment was done using the WHO-UMC causality assessment scale and it was found that 45 reports were under 'probable' and 15 were under 'possible' and 1 was 'certain' category (Figure 4). Among the 61 ADR reports, 12 were 'recovered', 39 were 'recovering', 5 were 'not recovered' and none of them were found to be 'fatal' (Figure 5).

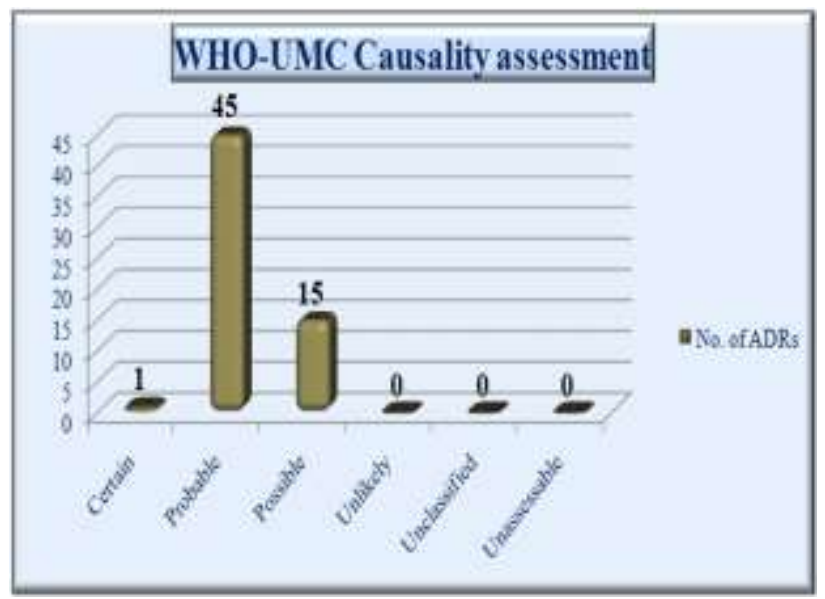

Figure 4: WHO-UMC causality assessment.

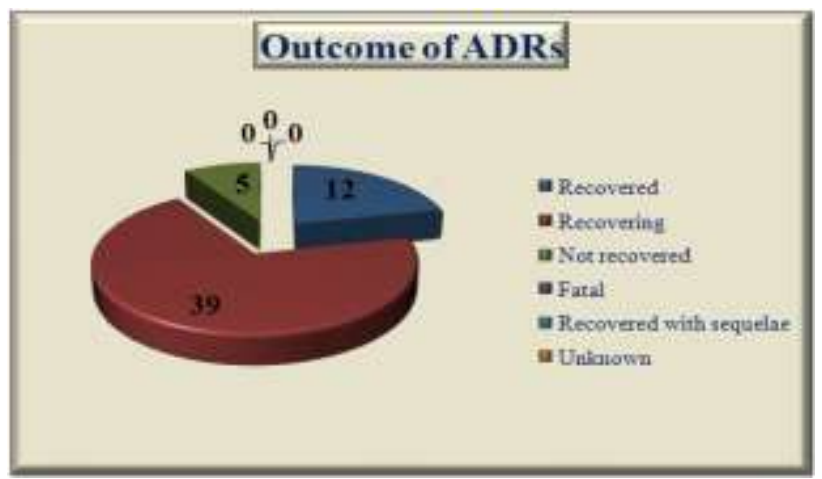

Figure 5: Outcome of ADRs.

\section{DISCUSSION}

From out study, it was found that the predominance of ADRs was in males than the females and similar findings were shown in the previous study by Singh et al but it is contrary to study of Alkhalil et al. ${ }^{1,8}$ The prevalence of ADRs due to AEDs is more in the middle-aged adult group which is contrary to Jayalekshmi et al but similar to the study by Gajjar et al. ${ }^{2,9}$

In our study the most of the ADRs due to AEDs belonged to SOC of 'skin and subcutaneous disorder's which is in line with the study of Khan et al, but differs from the study conducted by Singhal et al. ${ }^{10,11}$

In the study it was found that the most of the ADRs are implicated by phenytoin which was similar to the study of Khan et al, but contrary to the study of Rohit Singhal et al and Du et al. ${ }^{10-12}$ From the study it was found that the most of the ADRs were serious which is contrary to the study of Singhal et al and Du et al. ${ }^{11,12}$

In this study the WHO-UMC causality assessment scale was used and found that the most of the ADRs were under 
'probable' category which is contrast to $\mathrm{Du}$ et al, but similar to study of Sari et al in which Naranjo's causality assessment scale was used. ${ }^{12,13}$

\section{Limitations}

This was non-interventional, prospective observational study based on the spontaneous ADR reporting system with lack of denominator data, i.e.; total number of prescriptions with suspected drugs with study population. So, we could not quantify the risk of ADRs associated with the use of AEDs. Co-morbid conditions and other risk factors were not analyzed in this study. There is also possibility of under-reporting of ADRs due to AEDs.

\section{CONCLUSION}

Our study revealed that the prevalent ADRs were nonserious and most of ADRs were associated with phenytoin followed by carbamazepine. Antiepileptic drugs like phenytoin, carbamzepine and sodium valproate are the traditional and most sought-after choice in the management of epilepsy. Antiepileptic drugs are associated with many ADRs, which not only affects the physician's choice but also determine the acceptance of the drug by the patient. Monitoring adverse drug reactions in patients using antiepileptic drugs is a matter of importance. A robust pharmacovigilance practice is essential to detect, assess and prevent these ADRs by sensitizing the HCPs about the importance of ADR reporting at all levels to ensure patient safety.

\section{ACKNOWLEDGEMENTS}

We acknowledge the National Coordination CenterPharmacovigilance Program of India, Indian Pharmacopoeia commission, Ghaziabad for the logistic support and the physicians of Madras Medical College and Rajiv Gandhi Government General Hospital who have voluntarily reported the ADRs associated with the use of AEDs.

Funding: No funding sources Conflict of interest: None declared

Ethical approval: The study was approved by the Institutional Ethics Committee

\section{REFERENCES}

1. Handa N, Singh R. Monitoring of Adverse Drug Reactions of Anti-Epileptic Agents in the Neurology Department. Int J Health Sci Res. 2018;8(8):136-40.

2. Gajjar BM, Shah AM, Patel PM. The pattern of adverse drug events to antiepileptic drugs: A crosssectional study at a tertiary care teaching hospital.
National J Physiol Pharm Pharmacol. 2016;6(6):61621.

3. Nimesh S. A pharmacovigilance study of monitoring and focusing of adverse drug reactions induced by antiepileptic drugs used in epileptic patients. Pharm Pharmacol Int J. 2019;7(3):100-4.

4. Shanmugam S, Daniel L, Ahamed J. Meta-analysis of antiepileptic drugs induced Choreoathetosis in paediatric patients. Int $\mathrm{J}$ Med Rev Case Report. 2017;1(3):49-52.

5. Chol JH, Chan SP, Dong YK, Min GK, Sujeong K, Young MY, Sae HK, et al. Severe Cutaneous Adverse Reactions to Antiepileptic Drugs: A Nationwide Registry-Based Study in Korea. Allergy Asthma Immunol Res. 2019;11(5):69.

6. Zaccara G, Franciotta D, Perucca E. Idiosyncratic Adverse Reactions to Antiepileptic Drugs. Epilepsia. 2007;48(7):1223-44.

7. Ihtisham K, Ramanujam B, Srivastavaa S, Mehrab NK, Kaurc G, Khannad N, et al. Association of cutaneous adverse drug reactions due to antiepileptic drugs with HLA alleles in a North Indian population. Seizure: European J Epilepsy. 2019;66:99-103.

8. Alkhalil HJ, Sridhar SB, Rabbani SA, Omar AA. Intensive Monitoring of Adverse Drug Reactions to Antiepileptic Drugs in Neurology Department of a Secondary Care Hospital in U.A.E. J Young Pharmacist. 2019;11(2):192-6.

9. Jayalekshmi K, Palanisamy K, Ramanathan S, Akela S. A Study on the Adverse Drug Reactions Induced by Anti Epileptic Drugs in the Epileptic Patients. J Applied Pharmaceut Sci. 2016;6(5):119-23.

10. Khan SZ, Ali MA, Subhani G, Ushasree T. A study of serious adverse drug reactions with antiepileptic drugs: a pharmacovigilance study. Int J Basic Clin Pharmacol. 2018;7(5):922-5.

11. Singhal R, Ahmed K, Bhandri A, Santani DD. Newer Anti Epileptics: Adverse Drug Reactions Experience. J Pharm Res. 2012;5(2):1004-6.

12. Du Y, Lin J, Shen J, Ding S, Ye M, Wang L, et al. Adverse drug reactions associated with six commonly used antiepileptic drugs in southern China from 2003 to 2015. BMC Pharmacol Toxicol. 2019;20(1):7.

13. Sari SP, Salma NKS, Rianti A. Monitoring of anticonvulsant drug side effects in outpatients with epilepsy. Int J App Pharm. 2018;10(1):303-6.

Cite this article as: Mukhyaprana SK, Devipriya S, Thirumalaiappan M. Study of adverse drug reactions associated with antiepileptic drugs: a pharmacovigilance study using spontaneous reporting system. Int J Basic Clin Pharmacol 2021;10:1125-9. 